anti-syphilitic treatment the symptoms were relieved, but narrowing of the stomach was still present radiologically eight months after treatment had been started. In spite of this persistent deformity the patient had put on three stones in weight. In cases of this type where residual deformity persists after treatment, a genuine stenosis with obstruction may develop at a later date, even in the absence of active syphilis.

Eckhoff points out that it is characteristic of syphilitic lesions that the symptoms fail entirely to respond to the usual medical treatment for ulcer. The diagnosis of syphilis of the stomach may be made if :-

1. The patient has a history resembling that of gastric ulcer or neoplasm.

2. Radiological appearances indicate diffuse in- filtration of the stomach, with absence of peristalsis in the affected area, and rapid emptying time even when there is some narrowing of the stomach itself or of the pylorus.

3. The serological tests for syphilis are positive.

4. There is no response to an ulcer regime.

5. There is speedy symptomatic improvement with anti-syphilitic therapy.

I am grateful to Dr. Terence East, under whose care this case was originally admitted, for permission to publish this account.

\section{BIBLIOGRAPHY}

BOCKUS, H. L. (1946), 'Gastroenterology,' W. B. Saunders \& Co, Philadelphia and London.

PALMER, W. L., SCHINDLER, R., TEMPLETON, F. E., and HUMPHREYS, E. M. (r943), Arch. Int. Med., I8, 393.

ECKHOFF, N. L. (193I), Guy's Hospital Reports, 8 477. $x$.

\title{
FALSE LOCALIZING SIGNS IN CEREBRAL TUMOURS
}

\author{
By W. F. T. Tatlow, M.D., M.R.C.P.(Lond.) \\ Registrar and Tutor in Medicine, University of Bristol
}

Two cases, recently seen, showing symptoms due to the effects of chronic intracranial hypertension, are considered to be of sufficient interest to warrant a review of the literature relating to false localizing signs in cerebral tumours.

\section{Case 1}

A woman, aged 46 , was admitted to hospital with a four years' history of occipital headaches which occurred in attacks every few days. For the past year she had been having transient attacks of amaurosis, and for the past six months she had developed a complete anosmia which she had particularly noticed when cooking. Her rerelations had found that she had recently become somewhat dull and depressed.

Examination showed an alert and co-operative patient with no abnormality on neurological, cardiovascular or respiratory examination, except for a complete bilateral anosmia and a chronic papilloedema with secondary optic atrophy. A lumbar puncture showed a pressure of $280 \mathrm{~mm}$. of water, the cerebro-spinal fluid itself showing no abnormalities.

It was considered that the patient had an olfactory groove meningioma with serious visual loss from chronic intracranial hypertension. A ventriculogram, on the other hand, showed appearances suggestive of a tumour at the posterior end of the third ventricle, and the patient was eventually discharged without any biopsy findings. This patient's anosmia was probably due to the effects of chronic intracranial hypertension.

\section{Case 2}

A man, aged 37, was admitted to the Frenchay neuro-surgical unit with a six weeks' history of headache and vomiting. On examination the patient was found to be talkative, rational and cooperative, with a moderate nominal dysphasia, slight dyslexia and marked dysgraphia ; an 'explosive' character to his speech was noted as a prominent feature, suggestive of a cerebellar type of defect. The cranial nerves were normal except for bilateral blurring of the optic disc margins, a right upper quadrantic homonymous hemianopia, and a weakness of the lower part of the right side of the face. Appreciation of pain, temperature, touch and stereognostic sense was normal over the whole of the body, but there was found to be 
hypertonia and weakness of the right arm with a right extensor plantar response. In addition, bilateral cerebellar signs with inco-ordination, dysdiadokokinesia, dysmetria and intention tremor were found. An X-ray of the skull showed a pineal shift to the right. After an arteriogram, an exploratory craniotomy was performed; this showed a large infiltrating spongioblastoma in the left temporal lobe.

The presence of cerebellar signs in temporal lobe neoplasms is not uncommon, and suggestions as to the factors involved are discussed later ; in this particular case the pyramidal tract and visual field changes were, of course, of great diagnostic value as to the localization of the lesion and the cerebellar signs were in fact 'false localizing signs.'

Cerebral tumours may produce effects on structures far removed from their site of origin. The stresses and strains within the cranium are brought about by hydrocephalus, and direct pressure of distant nervous tissue against resistant dura or bone will produce physical signs which may mislead the diagnostician into placing the site of origin of the tumour in an entirely different situation from that which it really occupies.

Collier (1904) summarized the false localizing signs produced in high intracranial pressure, and a few have been added since by other authors. The incidence of false localizing signs, in a series of 161 cases of cerebral tumour studied by Collier, was 12.5 per cent. He pointed out that the most common sign in increased intracranial pressure was paresis of the sixth cranial nerves. He further suggested that high pressure produced brainstem traction, and that this resulted in tension on the sixth cranial nerves themselves, because of their more longitudinal course compared with the oblique or transverse course of others. Cushing (I910) pointed out that mere traction on a nerve does not cause palsy, and suggested that the aetiological factor might be strangulation of the sixth nerves by the transverse branches of the basilar artery at their exit from the pons ; actual indentation of the nerve by the artery was found by him. Wolff (1928) later drew attention to the fact that arteries are normally soft structures and press the nerve into the brain substance; he suggested that, as the sixth nerve is attached to the pons below and is he:i in the cavernous sinus above, pressure from above will press the sixth nerve against the sharp upper border of the petrous temporal bone. However, sixth nerve palsy must be regarded as of little localizing significance in cerebral tumours with evidence of increased intracranial pressure. In cases without such pressure, or in conjunction with fifth, seventh, eighth or ninth cranial nerve palsies, its presence can on the other hand have localizing value.

Collier (1904) discussed the changes in olfactory sense in high pressure, and stated that in his experience the olfactory nerves were rarely affected. Grey (I9I6) quotes Muskens (igro) as stating that olfactory sense disturbances are common in posterior fossa tumours, and goes on to describe impairment of olfactory sense in four out of 61 posterior fossa tumours with hydrocephalus. Cushing (1916) described a case of bilateral anosmia due to high pressure produced by a. cortical fibro-endothelioma; the olfactory disturbance was caused by mechanical injury, for herniation of the gyrus rectus and adjoining structures into a widened interclinoid.space had caused angulation of the olfactory nerves. Cushing went on to say that blunting of smell was a common accompaniment of posterior fossa tumours. Unilateral anosmia may be a very useful sign of a meningioma in the anterior cranial fossa ; but bilateral anosmia in patients with evidence of increased intracranial pressure should, on the other hand, be regarded as of little significance. In actual practice it may be difficult to decide the significance of even a unilateral anosmia, as deflected septa, sinusitis or head colds may be factors in its production.

Collier (1904) described a case of frontal tumour with sixth, seventh and eighth nerve palsies, with ipsilateral cerebellar signs; at autopsy "the cerebellum was indented by the edge of the foramen magnum.' He described, too, trigeminal symptoms with analgesia occurring over the peripheral fields in high intracranial pressure ; he also mentioned hemianopia as occurring, but gave no indication of the aetiological factors involved. $\mathrm{He}$ concluded by saying that the eighth nerves are rarely affected by high pressure.

Moore and Stern (1938) investigated the effects of high intracranial pressure on the subtentorial vessels ; they described cases with calcarine infarction which resulted from pressure on the posterior cerebral artery. The course of the posterior cerebral artery, after its division from the basilar artery, is in close relationship to the free edge of the tentorium cerebelli, and Moore and Stern suggested that compression of the vessel against this edge in supratentorial lesions would result in obstruction of the vessel with infarction of the calcarine cortex. The presence of homonymous hemianopia may be encountered rarely as a false localizing sign in cerebral tumours, and occurs only in those cases where the tumour is supratentorial in position and where a considerably raised pressure has produced coning.

Herniation of the uncus into the incisura tentorii in coning was first described by Meyer 


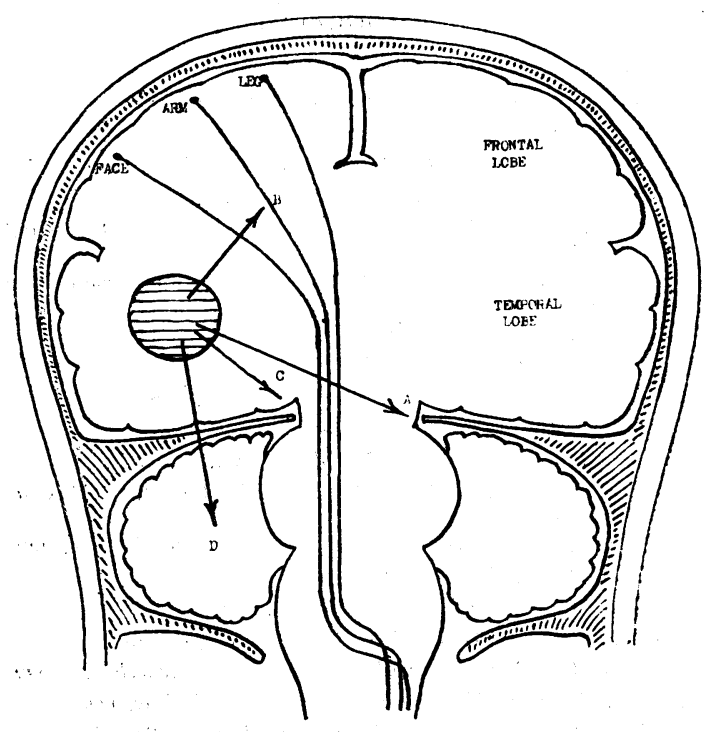

Adapted from Courville (1928) and Jefferson (1938).

(1920). In a series of 100 cases of supratentorial tumours investigated by Schwarz and Rosner (194I) such herniation occurred in 83 per cent. Kernohan and Woltman (r929) showed that motor signs occurring on the same side as a supratentorial tumour were due to pressure of the sharp tentorial edge against the opposite cerebral peduncle. The significance of unilateral pyramidal signs must therefore be related to the degree of intracranial hypertension present, and minor pyramidal signs occurring late in hydrocephalus must not be confused with the more major motor symptoms and signs occurring early in cortical lesions. A more important fact to be borne in mind is that these minor pyramidal signs in hydrocephalus are to be found on the same side as the tumour in contradistinction to those found on the opposite side in cortical tumours.

With regard to the pyramidal signs found in temporal lobe tumours, it will be seen from the diagram that these are likely to be varied. Pressure upwards at B will produce paresis maximum in the face and later in the arm on the opposite side ; pressure at $A$ (in which the crus is pressed against the opposite tentorium) will produce hemiplegic signs on the same side as the tumour, and pressure at $C$ will produce hemiplegic signs on the opposite side in addition to the effects seen at $A$ with resultant bilateral pyramidal effects. The midbrain may be involved in the herniation of the uncus when dilatation of the pupil on the same side as the lesion will result (Jefferson, 1938).

Cerebellar signs may be difficult to elucidate. Ataxia occurring with frontal tumours was first described by Bruns (1892); in a more recent series of cases studied by Frazier (1936) ataxia occurred in 49 per cent. of 150 frontal tumours. Frazier attributed the earlier unilateral cerebellar ataxia to involvement of the fronto-pontocerebellar pathways (without high pressure effects) and the later bilateral signs to high pressure coning.

Cerebellar signs, described by Knapp (1918), are not uncommon in temporal lobe neoplasms. Schwab (1925), quoted by Davidoff (1930), suggested that these contralateral equilibra:ory signs are due to involvement of temporopontine tracts, since they are present in lesions where there is no increased intracranial pressure, such as gu:shot wounds. Schwab's views do not seem to have been contraindicated, but a more reasonable suggestion is that of Courville (1928), for as may be seen from the diagram, pressure at $D$ will push the tentorium cerebelli down on to the cerebellum. Bailey (1924) described three suprasellar tumours with cerebellar signs, and suggested that pressure on the cerebellar pathways was the aetiological factor concerned, as in two of the cases extension of the tumour through the tentorium had occurred. Davidoff (1930) pointed out that cerebellar signs may be sufficiently prominent in pineal tumours to lead to a false diagnosis of an infratentorial lesion ; he gave no reason for this, but downward pressure on to the cerebellum from coning appears to be the most likely explanation.

Pituitary disorders may arise from chronic intracranial hypertension and Cushing (1921) described at some length the effects so produced. He pointed out that it had been recognized for some time that patients with cerebral tumours, especially children, often lose no weight in spite of continued vomiting. Hypopituitrism with adiposity, subnormal temperature, sexual infantilism and small stature is not uncommon in continued hydrocephalus, and misleading diagnoses may be made as X-rays in such cases often show enlargement of the sella. Hyperpituitrism, a much rarer concomitant of chronic intracranial pressure, may also occur. Cushing, in the same book, records a patient with acromegaly who was found at operation to have a cerebellar cyst producing hydrocephalus.

Astereognosis must nearly always be regarded as a cortical sign, and the usual situation of the lesion is found to be in the parietal lobe. Cases have been reported by various authors in which unilateral astereognosis has been present in infratentorial lesions. Roussy and Levy (r930) described a case of pontine glioma invading the first and second cervical segments ; the physical signs included brisk tendon reflexes and an extensor plantar response on the same side as a cortical sensory loss. An exploration of the 
parietal area was made, but with negative results, and only at autopsy was the correct anatomical diagnosis made. No explanation for this cortical sensory loss was given by these authors, and they did not suggest the exact anatomical pathway involved; they pointed out, however, that the presence of suboccipital headache and involvement of bulbar cranial nerves should be of localizing value if present. Other similar cases have been reported by Cushing and Bailey (1928), Lereboullet (1932) and Delay (1933).

\section{Summary}

Two cases with false localizing signs in cerebral tumours are described, and the literature relating to such effects is briefly reviewed.

I wish to thank Mr. G. L. Alexander and Mr. D. G. Phillips of the Frenchay Neuro-Surgical Unit for permission to use their case notes, and to Dr. A. M. G. Campbell of the Bristol Royal Infirmary for help and criticism in writing this article.

\section{BIBLIOGRAPHY}

BAILEY, P. (1924), Arch. Neur. Psych., 11, 37.

BRUNS, L. (1892), Deutsche Med. Wchnschr., 18, 138.

COLLIER, J. (1904), Brain, 27, 490.

COURVILLE, C. (1928), California 50 West Med. F., 29, 2.

CUSHING, H. (1916), f. Nerv. छ Ment. Dis., 44, 415.

CUSHING, H. (1912) 'The Pituitary Body and its Disorders,' J. B. Lippincott, Philadelphia, p. r9r.

CUSHING, H., and BAILEY, P. (1928), 'Tumours arising from blood vessels of the brain,' Thomas, Baltimore.

DAVIDOFF, L. M. (1930), Psychiat. Quart., 4, 579.

DELAY, J. P. L. (1935), Thèse de Paris.

JEFFERSON, G. (1938), Arch. Neur. Psych., 40, 857.

FRAZIER, C. (1936), Arch. Neur. Psych., 35, 525.

GREY, E. C. (1916), Bull. fohns Hopkins Hosp., 27, 274.

KERNOHAN, J. W., and WOLTMAN, H. W. (1929), Arch: Neur. Psych., 21, 274.

KNAPP, A. (1918), Zeitschr. f.d. ges Neurol. u. Psychiat., 42, 226. LEREBOULLET, T. J. (1932), These de Paris.

MEYER, A. (1920), Arch. Neur. Psych., 4, 387.

MOORE, M. T., and STERN, K. (1938), Brain, 6r, 70.

MUSKENS (1910), Lewandowsky's Handbuch der Neurolgie, 1, 977. ROUSSY, G. and LEVY, G. (1930), Rev. Neurologique, 145 .

SCHWAB, O. (1925), Deutsche Zeitschr. f. Nervenh:, 84, 38.

SCHWARZ, G., and ROSNER (194I), Arch. Neur. Psych., 46, 297. WOLFF, E. (1928), Brit. F. Ophth., 12, 22.

\section{RUTHIN CASTLE, NORTH WALES}

A Clinic for the diagnosis and treatment of Internal Diseases (except Mental or Infectious Diseases). The Clinic is provided with a staff of doctors, technicians and nurses.

The surroundings are beautiful. The climate is mild. There is central heating throughout. The annual rainfall is 30.5 inches, that is, less than the average for Er.gland.

The Fees are inclusive and vary according to the room occupied.

For particulars apply to THE SECRETARY. Ruthin Castle, North Wales.

Tolograms: Castle, Ruthin.

Telephone: Ruthin 66 